\title{
Micro-crack Pinning and Interfacial Fracture in Mixed Metal Oxide Reinforced Epoxy Nanocomposite
}

\author{
Ramakrishna Vasireddi and D. Roy Mahapatra
}

\author{
(Submitted October 24, 2017; in revised form September 5, 2018; published online October 11, 2018)
}

\begin{abstract}
The effects of mixed metal oxides $\left(\mathrm{Ce}_{x} \mathrm{Zr}_{1-x} \mathrm{O}_{2}\right)$ nanoparticle dispersion on the mechanical properties and fracture mechanisms of epoxy polymer matrix and its composite with glass fiber system are reported in this paper. $\mathrm{Ce}_{x} \mathrm{Zr}_{1-x} \mathrm{O}_{2}$ nanoparticles are synthesized using sol-gel method, and its crystallinity is optimized. Epoxy nanocomposites are synthesized by a dispersion technique, and the compressive properties are optimized. The glass transition temperature has been improved. Epoxy with 5 wt.\% of $\mathrm{Ce}_{0.75} \mathrm{Zr}_{0.25} \mathrm{O}_{2}$ shows optimal results with an increase of $17.4 \%$ in compressive modulus, and an increase of $23.4 \%$ in compressive strength with respect to those of neat epoxy. This improvement attributes to higher strength of shearing of polymer during the fracture of the nanoparticle interface. Micro-crack kinks at the interfaces can further delay fracture under compression. E-glass fabric-reinforced 5 wt. \% $\mathrm{Ce}_{0.75} \mathrm{Zr}_{0.25} \mathrm{O}_{2}-\mathrm{epoxy}$ nanocomposite also shows improvement in the mechanical properties via nanoscale interface with fibers. This type of ceramic nanocomposites has useful applications in thermal/electrical insulations besides improving the compressive/buckling properties.
\end{abstract}

Keywords ceramic, glass fabric, interface fracture, micro-crack, nanoparticles, nanocomposite, oxide, zirconia

\section{Introduction}

Epoxy matrix-based structural components provide excellent mechanical, thermal, and electrical properties. Moreover, the epoxy resins are well-established thermosetting matrices for advanced composites for high stiffness, specific strength, dimensional stability, chemical resistance, and the ease of processing along with strong adhesion to the bonded/embedded reinforcement (Ref 1). The incorporation of inorganic fillers to polymer for improving the performance of the final product has long been an essential industrial activity (Ref 2). Microscale filler particulates have been extensively used in epoxy composites (Ref 3). The resultant composites had enhanced stiffness, strength, and toughness individually or together via various microscale mechanisms. However, the micro-fillers may reduce other important properties, such as the impact resistance, and cause an adverse effect on the processability of the required final material. The nanoparticle-reinforced composite has much higher number of particles per unit area in comparison with the micron-sized particle composite, which causes a small crack propagating through the material, and hence the energy consumption for crack propagation increases, and hence improves the impact resistance of the nanocomposite (Ref 4, 5).

One possible solution for the above problem is to use smaller fillers with dimensions in the range of nanometer scale. The advantages of small fillers are that they can be homoge-

Ramakrishna Vasireddi and D. Roy Mahapatra, Department of Aerospace Engineering, Indian Institute of Science, Bangalore 560012, India. Contact e-mail: ranky.phy@gmail.com. neously distributed within the polymer by various techniques, thereby paving way for an efficient reinforcement effect with enhanced ductility and impact strength and improving the wear resistance and reducing the residual stresses (Ref 6). Suitable nanoparticles can produce good wettability with the thermoset polymer and fill in the small gaps between the crosslinked polymer chains, providing high resistance to deformations under stress. Nanoparticle reinforcements can reduce the thermal expansion coefficient and increase thermal and wear resistance of the host matrix. This is due to the material interfaces that are enhanced by the synergetic effect between the micro-reinforcement and the nanostructure, creating better interfaces and henceforth resulting in interesting improvements in the thermal and mechanical properties (Ref 7-9). On the other hand, previous works have indicated that as a class of porous materials can greatly improve the tribological and mechanical properties of an epoxy matrix composite and to achieve a self-lubricating material (Ref 10,11).

Mixed metal oxides are known for their high thermal stability and resistance to sintering (Ref 12). Zirconia $\left(\mathrm{ZrO}_{2}\right)$ is a known choice for thermal barrier coatings (TBCs) (Ref 13). The use of zirconia in polymer has useful applications in thermal management (Ref 14) and radiation shielding (Ref 15). It is well known that $\mathrm{ZrO}_{2}$ phases need to be stabilized by doping metal oxides such as $\mathrm{CeO}_{2}, \mathrm{Y}_{2} \mathrm{O}_{3}, \mathrm{CaO}, \mathrm{MgO}$ (Ref 16). Ceria-stabilized zirconia has higher fracture toughness and high thermal stability compared to yttria-stabilized zirconia (Ref 17). In $\mathrm{CeO}_{2}$, the replacement of $\mathrm{Ce}$ ions by cations of a different size modifies the ion mobility and the lattice structure, resulting in the formation of a defective fluorite structure. Such modifications in the defect structure are able to impart improved properties to the materials, such as better resistance to sintering at elevated temperatures, better thermal and mechanical properties (Ref 18, 19). Recently, some ceramic nanoparticles such as $\mathrm{SiC}, \mathrm{Al}_{2} \mathrm{O}_{3}, \mathrm{SiO}_{2}, \mathrm{WO}_{3}, \mathrm{CeO}_{2}$, and $\mathrm{ZrO}_{2}$ have already been used to reinforce polymer matrix (Ref 2024). All of them have demonstrated their ability to enhance the mechanical behavior of epoxy matrix and in some cases to 
improve their toughness. The superior properties of metal oxides such as hardness, compressive strength, thermal resistance, and wear resistance make them suitable for their application as reinforcement material in polymer matrices (Ref 25-27). Mixed metal oxide nanoparticles due to phase stability, thermal stability, and high surface area-to-volume ratio have increased interfacial interaction between nano-reinforcement and host polymer matrix; thus, better adhesion between resin and filler is achieved. Researchers have used several techniques for dispersing nanoparticles by mechanical agitations, such as ball milling or magnetic stirring, ultrasonic vibration, shear mixing, noncontact mixing, and the use of dispersing agent (Ref 28). In the present investigation, we used shear mixer followed by sonication to prepare all the specimens.

Glass fiber-reinforced polymer (GFRP) composites due to their high specific strength, stiffness, corrosion resistance, and good dielectric properties have become attractive materials in aerospace, automobile industries, marine, armor, microelectronic packaging, electronic circuit board, and civil engineering structures (Ref 29-33). Hence, the use of mixed metal oxide nanoparticles in GFRP composite is a potential way to enhance its thermal, electrical, radiation shielding, and mechanical properties to a large extent.

However, till date, no studies have reported the mechanical performance of mixed metal oxides-incorporated epoxy composite and glass fiber system. In the present research, we report the effect of mixed metal oxides on the mechanical behavior of epoxy nanocomposites with variation in $\mathrm{Ce}_{x} \mathrm{Zr}_{1-x} \mathrm{O}_{2}$ concentrations. Further, we have investigated the effect of an optimally synthesized $\mathrm{Ce}_{0.75} \mathrm{Zr}_{0.25} \mathrm{O}_{2}$ system on the property improvement of E-glass fabric-reinforced laminates.

\section{Materials and Methods}

\subsection{Mixed Metal Oxide Nanoparticle Optimization}

The $\mathrm{Ce}_{x} \mathrm{Zr}_{1-x} \mathrm{O}_{2}$ solid solution powders were prepared using sol-gel method. The solid solution was then dried at $100{ }^{\circ} \mathrm{C}$ for $6 \mathrm{~h}$. The dried materials were later milled into fine powders and were calcined at three different temperatures, viz. at 500, 700, and $900{ }^{\circ} \mathrm{C}$, for $8 \mathrm{~h}$ to study their crystallinity. Cerium(III) nitrate hexahydrate (Aldrich, USA) and zirconium(IV) oxyni- trate hydrate (Aldrich, USA) were used as sources of Ce and Zr, respectively. Ammonium hydroxide (Merck, India) was used as the precipitating agent.

The phases of $\mathrm{Ce}_{x} \mathrm{Zr}_{1-x} \mathrm{O}_{2}$ nanoparticles were analyzed using powder $\mathrm{x}$-ray diffraction (XRD, PANalyticalX'PERT PRO). The morphology, fracture surface, and interfacial bonding with matrix and E-glass fabric of the tested composites discussed in the later section are observed using FESEM (Ultra 55, Carl Zeiss, GEMINI).

Figure 1(a) shows the XRD patterns of $\mathrm{Ce}_{x} \mathrm{Zr}_{1-x} \mathrm{O}_{2}$ powders calcined at $700{ }^{\circ} \mathrm{C}$ for $8 \mathrm{~h}$ at various positions along $x$ direction. It can be observed that the diffraction peaks were shifted to lower angle with increasing Ce content up to $x=0.75$ and no peak shift was observed with $\mathrm{Ce}$ content higher than $x=0.75$. As compared to the XRD pattern of $\mathrm{CeO}_{2}$ alone, the XRD peaks observed for $\mathrm{Ce}_{x} \mathrm{Zr}_{1-x} \mathrm{O}_{2}$ solid solutions become broader, indicating a distortion of the cubic phase of the fluorite structure to a tetragonal one due to the incorporation of $\mathrm{ZrO}_{2}$ into $\mathrm{CeO}_{2}$. Figure 1 (b) shows the FESEM micrographs of the calcined $\mathrm{Ce}_{0.75} \mathrm{Zr}_{0.25} \mathrm{O}_{2}$ powders at $700{ }^{\circ} \mathrm{C}$ with average size ranging between 10 and $20 \mathrm{~nm}$. Optimized composition of $\mathrm{Ce}_{0.75} \mathrm{Zr}_{0.25} \mathrm{O}_{2}$ is used for further dispersion in epoxy system due to its better phase stabilization.

\subsection{Optimization of Nanoparticle Dispersion in Epoxy Matrix}

Commercially available epoxy phenol novolac resin, Araldite LY 5052 (Huntsman Advanced Materials, India), has been used as matrix for the nanoparticle reinforcement. Aradur $5052 \mathrm{CH}$ (India) was used as curing agent for Araldite LY 5052.

The optimized $\mathrm{Ce}_{0.75} \mathrm{Zr}_{0.25} \mathrm{O}_{2}$ nanoparticles were added to epoxy resin in an optimal manner (wt.\% varying from 0 to 10 ). The solution was obtained using shear mixer followed by sonication for $15 \mathrm{~min}$. Hardener ( $38 \%$ by weight of epoxy) was then added and mixed to cure the resin. The obtained mixtures were poured into cylinder-shaped molds having dimensions of $12 \times 6 \mathrm{~mm}^{2}$ and were allowed to cure at room temperature for $24 \mathrm{~h}$ with continuous spinning to develop uniform dispersion and avoid any settling of the nanoparticles. It was then cured at $50{ }^{\circ} \mathrm{C}$ for $15 \mathrm{~h}$ and subjected to vacuum for $24 \mathrm{~h}$ to remove trapped air bubbles. The schematic of the fabrication process is shown in Fig. 2.

The compressive mechanical and thermal properties of the composites were determined using universal testing machine (UTM, Makron-Biss) and Dynamical Mechanical Analyzer
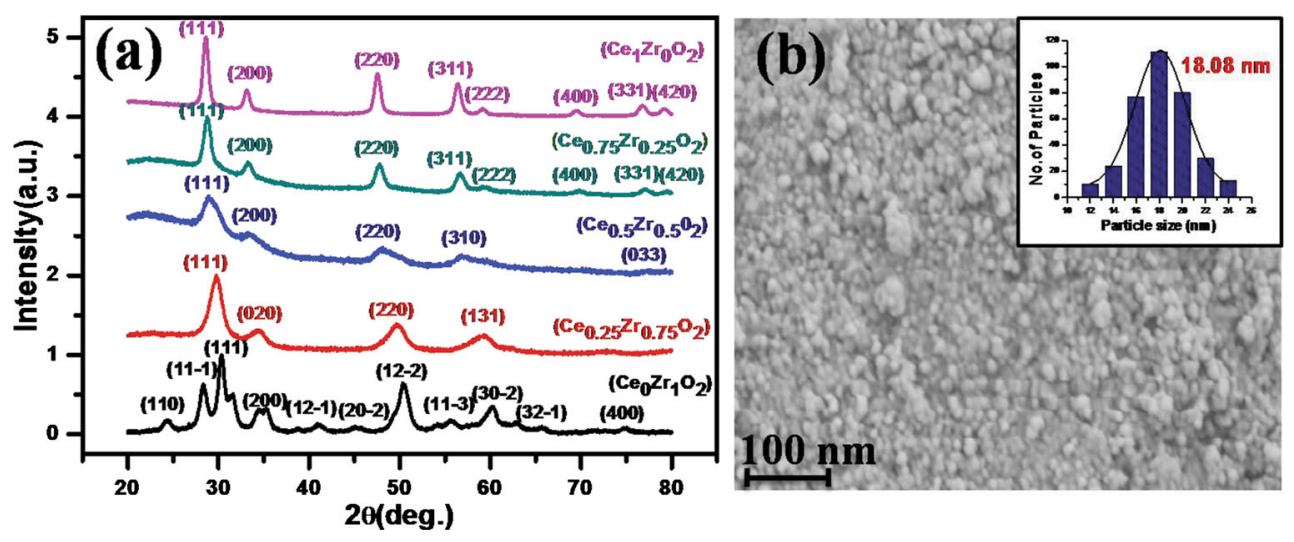

Fig. 1 (a) XRD patterns of $\mathrm{Ce}_{x} \mathrm{Zr}_{1-x} \mathrm{O}_{2}$ solid solution and (b) FESEM micrograph of $\mathrm{Ce}_{0.75} \mathrm{Zr}_{0.25} \mathrm{O}_{2}$ solid solution powders calcined at $700{ }^{\circ} \mathrm{C}$ for $8 \mathrm{~h}$ 


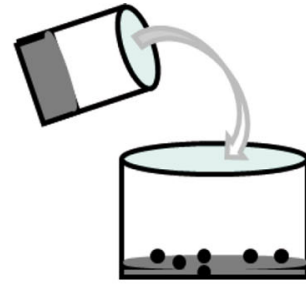

Nanoparticles/Epoxy mixing under sonicator

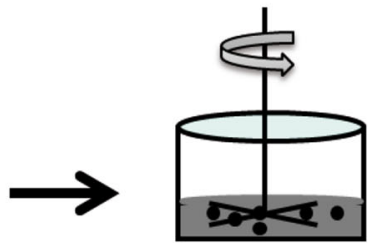

High speed shear mixing

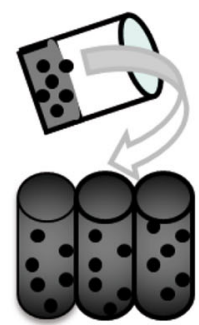

Pouring into moulds

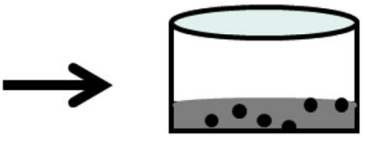

Desiccation for removin air bubbles

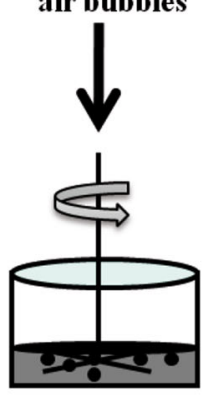

Shear mixing after hardener addition

Fig. 2 Schematic diagram showing ceramic-epoxy nanocomposite synthesis steps

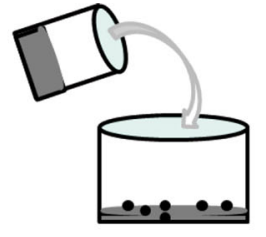

Nanoparticles/Epoxy mixing under sonicator

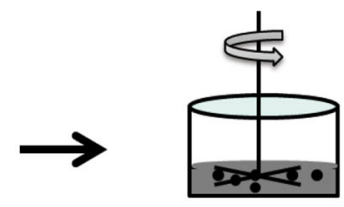

High speed shear mixing

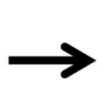

Desiccation for removing

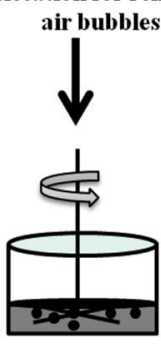

Shear mixing after hardener addition

Fig. 3 Schematic diagram of epoxy-5 wt.\% $\mathrm{Ce}_{0.75} \mathrm{Zr}_{0.25} \mathrm{O}_{2}$ /glass fabric laminate fabrication process

(DMA, MetraVib). Burnout testing was performed in a muffle furnace. Specimens as well as crucibles were initially cleaned using acetone and dried in the vacuum for a day to eliminate any moisture/impurities. Specimens were then placed in the weighed crucible, and the weight was recorded along with the crucible. The specimens were then heated at different temperatures $\left(25-350^{\circ} \mathrm{C}\right)$ with a half-hour holding at constant temperature till the specimens were charred. The weight difference at each temperature was recorded. All the compression tests were carried out in accordance with ASTM 695, and the specimen dimensions were kept as $12 \times 6 \mathrm{~cm}^{2}$ for the test. For all the specimens the dimensional tolerance was ensured by polishing the sample within $2-\mu \mathrm{m}$ variation to avoid generation of stresses at the sample edges.

\subsection{Dispersion of Nanoparticle-Epoxy Matrix in Glass Fabric}

The optimized nanocomposite matrices (5 wt.\% $\mathrm{Ce}_{0.75}$ $\mathrm{Zr}_{0.25} \mathrm{O}_{2}$ ) were infused into the unidirectional $\left[0^{0}\right]_{5}$ GFRP laminates by hand lay-up technique as shown in Fig. 3. The specimens are cured in the vacuum at room temperature for $24 \mathrm{~h}$. Tensile specimens are thereafter laser-cut and polished to the desired dimensions. In order to achieve better performance, the composites were then post-cured at $50{ }^{\circ} \mathrm{C}$ for $15 \mathrm{~h}$ and subjected to vacuum for $24 \mathrm{~h}$, as discussed in the previous section. Unidirectional E-glass fabric with fiber size of $9 \mu \mathrm{m}$, yarn size of $66 \mathrm{TEX}$, fabric thickness of $0.3 \mathrm{~mm}$ and GSM of 260 is used as the fiber reinforcement phase. 

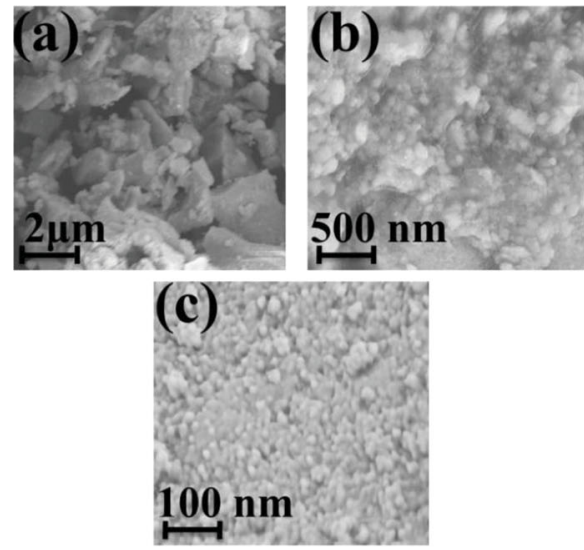

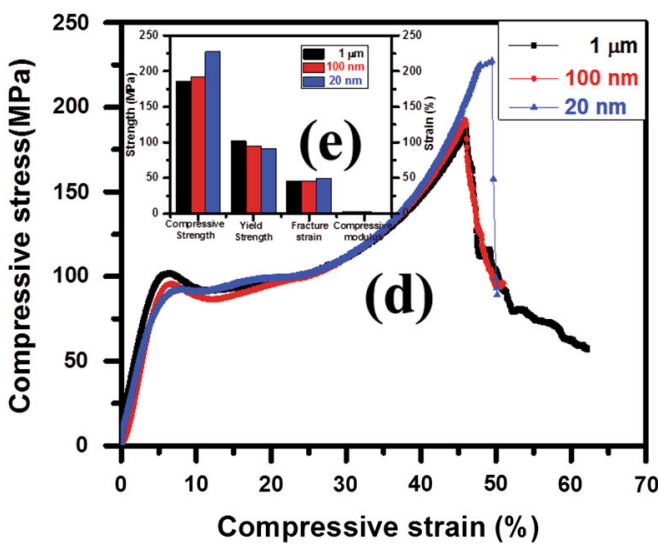

Fig. 4 FESEM micrographs of $\mathrm{Ce}_{0.75} \mathrm{Zr}_{0.25} \mathrm{O}_{2}$ : (a) $1 \mu \mathrm{m}$, (b) $100 \mathrm{~nm}$, (c) $20 \mathrm{~nm}$; (d) compressive stress-strain curves of corresponding particle size variation; and (e) compressive strength vs. particle size of $\mathrm{Ce}_{0.75} \mathrm{Zr}_{0.25} \mathrm{O}_{2}$

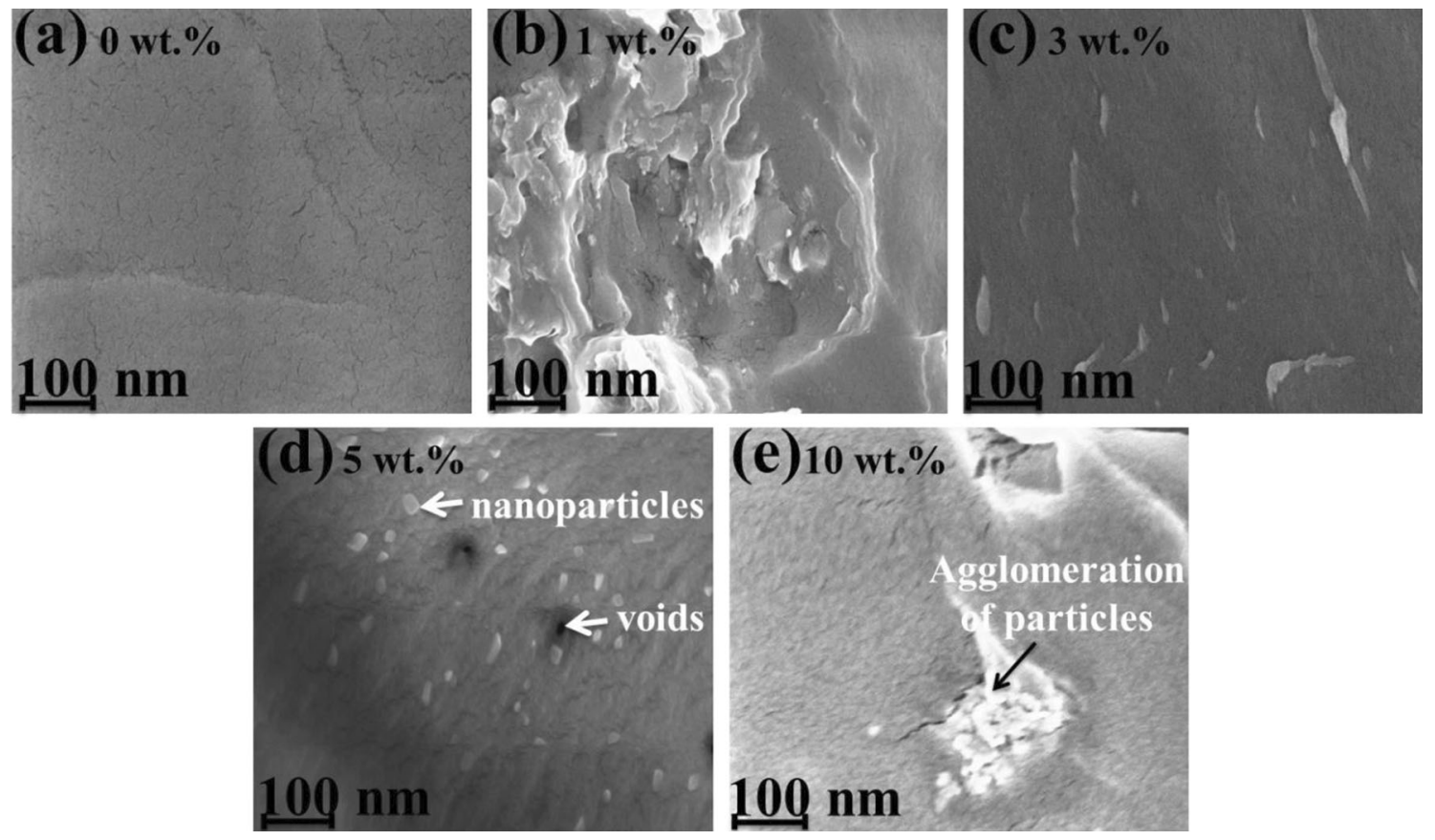

Fig. 5 FESEM micrographs of (a) pure epoxy and epoxy- $\mathrm{Ce}_{0.75} \mathrm{Zr}_{0.25} \mathrm{O}_{2}$ with (b) 1 wt.\%, (c) 3 wt.\%, (d) 5 wt.\%, and (e) 10 wt.\%

\section{Results and Discussion}

\subsection{Effect of Nanoparticle Structure and Properties on Nanocomposite Matrix}

Enhancements of the mechanical properties of the epoxy due to the mixed metal oxides were studied systematically. Figure 4(a), (b) and (c) shows the FESEM micrographs of varying particle sizes of $\mathrm{Ce}_{0.75} \mathrm{Zr}_{0.25} \mathrm{O}_{2}$. The effect of particle size on the composite strength of epoxy- $\mathrm{Ce}_{0.75} \mathrm{Zr}_{0.25} \mathrm{O}_{2}$ nanocomposites is shown in Fig. 4(d) and (e), where the average size is $1 \mu \mathrm{m}, 100$ and $20 \mathrm{~nm}$, respectively. It can be seen that the particle size effect clearly enhanced the compressive stress-strain behavior of the epoxy- $\mathrm{Ce}_{0.75} \mathrm{Zr}_{0.25} \mathrm{O}_{2}$ nanocomposite. The addition of nanoparticles into epoxy polymer increases the strength due to higher surface area, which can promote stress transfer from matrix to nanoparticles.
In contrast, the presence of microparticles, the reduction in strength, and failure strain demonstrated that the load transfer between matrix and microparticles is insufficient and the interface is weak (Fig. 4d). This suggests that smaller particles introduce additional mechanisms of energy absorption during compression.

Dispersion of nanoparticles in polymers is a crucial factor in determining the final properties of the nanocomposites. In this study, we have followed (section 2.2) different approaches to achieve very good particle distribution at the nanoscale. Figure 5(a), (b), (c), (d) and (e) shows the FESEM micrographs of pure epoxy and $\mathrm{Ce}_{0.75} \mathrm{Zr}_{0.25} \mathrm{O}_{2}$ nanoparticles (Fig. 1b) dispersed in epoxy with varying wt.\%. It can be seen that the proposed fabrication steps produced excellent particle dispersion at $5 \mathrm{wt} \%$ in the matrix system (Fig. 5d). There is no agglomeration of nanoparticles for $5 \mathrm{wt} . \%$, although at the highest concentration of $\mathrm{Ce}_{0.75} \mathrm{Zr}_{0.25} \mathrm{O}_{2}$ nanoparticles a small 

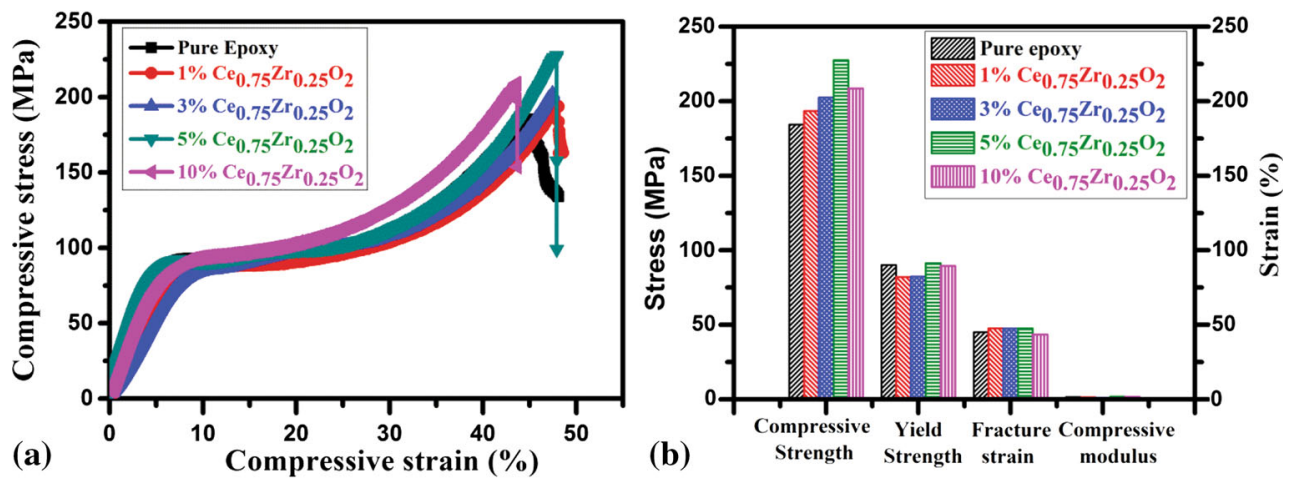

Fig. 6 (a) Compressive stress-strain curves of different wt.\% of $\mathrm{Ce}_{0.75} \mathrm{Zr}_{0.25} \mathrm{O}_{2}$ in the epoxy matrix nanocomposites. (b) Compressive strength vs. wt.\% of $\mathrm{Ce}_{0.75} \mathrm{Zr}_{0.25} \mathrm{O}_{2}$

Table 1 Sample weight ratios and compression properties of epoxy-Ce.75 $\mathrm{Zr}_{0.25} \mathrm{O}_{2}$ nanocomposites

\begin{tabular}{|c|c|c|c|c|c|}
\hline \multirow[b]{2}{*}{ Compressive property } & \multicolumn{5}{|c|}{$\mathrm{Ce}_{0.75} \mathrm{Zr}_{0.25} \mathrm{O}_{2}$ dispersed in epoxy } \\
\hline & Pure epoxy & $1 \%$ & $3 \%$ & $5 \%$ & $10 \%$ \\
\hline Compressive modulus, GPa & $1.66 \pm 0.3$ & $\begin{array}{l}1.45 \pm 0.13 \\
(12.6 \% \downarrow)\end{array}$ & $\begin{array}{l}1.21 \pm 0.1 \\
(27.1 \% \downarrow)\end{array}$ & $\begin{array}{l}1.95 \pm 0.8 \\
(17.4 \% \uparrow)\end{array}$ & $\begin{array}{l}1.75 \pm 0.7 \\
(5.4 \% \uparrow)\end{array}$ \\
\hline Compressive strength, $\mathrm{MPa}$ & $184.34 \pm 3.4$ & $\begin{array}{l}193.40 \pm 2.4 \\
(4.9 \% \uparrow)\end{array}$ & $\begin{array}{l}202.32 \pm 6.2 \\
(9.7 \% \uparrow)\end{array}$ & $\begin{array}{l}227.55 \pm 7.6 \\
(23.4 \% \uparrow)\end{array}$ & $\begin{array}{l}208.47 \pm 0.6 \\
(13.1 \% \uparrow)\end{array}$ \\
\hline Compressive yield, $\mathrm{MPa}$ & $90.09 \pm 0.4$ & $\begin{array}{l}82.03 \pm 4.3 \\
(8.9 \% \downarrow)\end{array}$ & $\begin{array}{l}82.29 \pm 5.1 \\
(8.6 \% \downarrow)\end{array}$ & $\begin{array}{l}91.40 \pm 1.3 \\
(1.5 \% \uparrow)\end{array}$ & $\begin{array}{l}89.51 \pm 0.3 \\
(0.6 \% \downarrow)\end{array}$ \\
\hline Compressive failure strain, $\%$ & $45.14 \pm 0.6$ & $\begin{array}{l}47.64 \pm 0.2 \\
(5.5 \% \uparrow)\end{array}$ & $\begin{array}{l}47.43 \pm 0.3 \\
(5 \% \uparrow)\end{array}$ & $\begin{array}{l}47.59 \pm 0.3 \\
(5.4 \% \uparrow)\end{array}$ & $\begin{array}{l}43.53 \pm 0.8 \\
(3.5 \% \downarrow)\end{array}$ \\
\hline
\end{tabular}

degree of agglomeration is observed. This is because the presence of more van der Waals forces between the nanoparticles would limit its dispersion (Fig. 5e). This is subsequently used as an optimal concentration for dispersion in the epoxyceramic-GFRP system.

The effect of nano- $\mathrm{Ce}_{0.75} \mathrm{Zr}_{0.25} \mathrm{O}_{2}$ on the compressive stress-strain response of the epoxy polymer is illustrated in Fig. 6(a). Compression tests reveal that the increase in the compressive strength of epoxy matrix takes place with an increase of up to 5 wt. $\%$ of $\mathrm{Ce}_{0.75} \mathrm{Zr}_{0.25} \mathrm{O}_{2}$. Compressive strength of pure epoxy is $184.3 \mathrm{MPa}$, which increased to 227.6 MPa for 5 wt.\% of $\mathrm{Ce}_{0.75} \mathrm{Zr}_{0.25} \mathrm{O}_{2}$. Compressive modulus and compressive strength are shown in Table 1. An increase in the compressive strength with an increase in the concentration of up to $5 \mathrm{wt} . \%$ is a result of high strength and hardening behavior of $\mathrm{Ce}_{0.75} \mathrm{Zr}_{0.25} \mathrm{O}_{2}$ nanoparticles dispersed uniformly in the resin with very high interfacial area between matrix and nanoparticles, thus enhancing the resistance to interfacial fracture. The presence of 5 wt. $\%$ of $\mathrm{Ce}_{0.75} \mathrm{Zr}_{0.25} \mathrm{O}_{2}$ improved ductility and promoted higher plastic hardening behavior after yielding. The property enhancement is due to homogeneous dispersion nanoparticles in the matrix as shown in Fig. 5(d) (Ref 34). The compressive strength and modulus decreased upon increasing the $5 \mathrm{wt} \% \%$ (Table 1). This decrease can be due to the agglomeration of nanoparticles, thus reducing the interfacial area for stress transfer from matrix. Regions around the agglomerated nanoparticles develop thermal stresses during curing cycle due to the mismatch of thermal expansion coefficient between epoxy matrix and $\mathrm{Ce}_{0.75} \mathrm{Zr}_{0.25} \mathrm{O}_{2}$ aggregate.
Other than that, agglomerates in the matrix cause a propagation crack and induce the initiation of the final failure. Therefore, the particle dispersion optimization conditions and size of the particles are playing role for mechanical property improvements.

To understand the mechanical behavior of the epoxy$\mathrm{Ce}_{x} \mathrm{Zr}_{1-x} \mathrm{O}_{2}$ nanocomposites, compression tests were carried out for all samples along the various positions along $\mathrm{x}$ direction. It is observed from Fig. 7 that the compressive strength of the $\mathrm{Ce}_{0.75} \mathrm{Zr}_{0.25} \mathrm{O}_{2}$ nanoparticle epoxy system is higher than that of all other samples. This confirms the higher stiffness and all other mechanical characterization of that composition in correlation with the phases shown in the XRD patterns in Fig. 1. This is because ceria-stabilized zirconia has higher fracture toughness and high thermal stability (Ref 17). Moreover, the stabilized cubic structure with zirconia content enhances $\left(\mathrm{Ce}_{0.75} \mathrm{Zr}_{0.25} \mathrm{O}_{2}\right)$ the mechanical properties. It is clear that the infusion of $\mathrm{Ce}_{0.75} \mathrm{Zr}_{0.25} \mathrm{O}_{2}$ nanoparticles also resulted in uniform dispersion of nanoparticles over the entire volume of epoxy resin and there are no adverse reactive effects. These results indicate the overall improvement of compressive behavior of epoxy-Ce $\mathrm{Ce}_{0.75} \mathrm{Zr}_{0.25} \mathrm{O}_{2}$ system (see Table 2). Compressive strength of pure $\mathrm{ZrO}_{2}$ sample was $188.4 \mathrm{MPa}$ which increased to a $227.5 \mathrm{MPa}$ for $\mathrm{Ce}_{0.75} \mathrm{Zr}_{0.25} \mathrm{O}_{2}$ sample. An increase in $\mathrm{Ce}$ concentration up to pure $\left(\mathrm{CeO}_{2}\right)$ caused a decrease in compressive strength, and the trend is shown in Fig. 7.

In order to study the fracture mechanism of mixed metal oxide nanoparticles in the epoxy, a controlled fracture tough- 

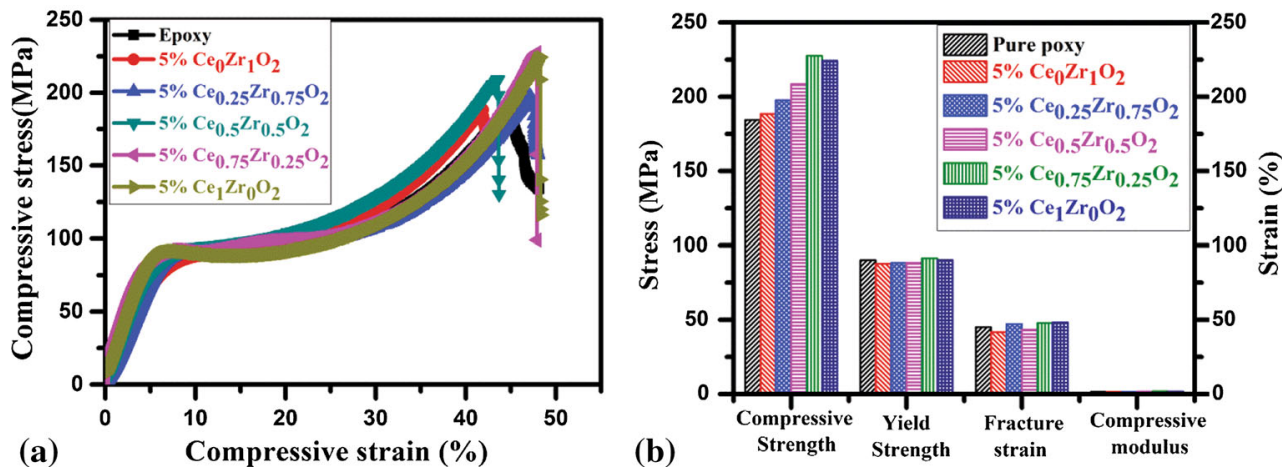

Fig. 7 (a) Compressive stress-strain curves of different concentrations of epoxy- $\mathrm{Ce}_{x} \mathrm{Zr}_{1-x} \mathrm{O}_{2}$ nanocomposites, (b) compressive strength vs. different concentrations of epoxy-5 wt. $\% \mathrm{Ce}_{x} \mathrm{Zr}_{1-x} \mathrm{O}_{2}$

Table 2 Sample weight ratios and compressive properties of epoxy-Ce $\mathrm{Zr}_{1-x} \mathrm{O}_{2}$ nanocomposites

\begin{tabular}{|c|c|c|c|c|c|c|}
\hline \multirow[b]{2}{*}{ Compressive property } & \multicolumn{6}{|c|}{ Nano-Ce $Z_{x} \mathrm{r}_{1-x} \mathrm{O}_{2}$ filled with epoxy } \\
\hline & Pure epoxy & $\mathrm{Ce}_{0} \mathrm{Zr}_{1} \mathrm{O}_{2}$ & $\mathrm{Ce}_{0.25} \mathrm{Zr}_{0.75} \mathrm{O}_{2}$ & $\mathrm{Ce}_{0.5} \mathrm{Zr}_{0.5} \mathrm{O}_{2}$ & $\mathrm{Ce}_{0.75} \mathrm{Zr}_{0.25} \mathrm{O}_{2}$ & $\mathrm{Ce}_{1} \mathrm{Zr}_{0} \mathrm{O}_{2}$ \\
\hline Compressive modulus, GPa & $1.66 \pm 0.3$ & $\begin{array}{l}1.62 \pm 0.7 \\
(2.4 \% \downarrow)\end{array}$ & $\begin{array}{l}1.53 \pm 0.4 \\
(7.8 \% \downarrow)\end{array}$ & $\begin{array}{l}1.76 \pm 0.4 \\
(6.0 \% \uparrow)\end{array}$ & $\begin{array}{l}1.95 \pm 0.8 \\
(17.4 \% \uparrow)\end{array}$ & $\begin{array}{l}1.77 \pm 0.3 \\
(6.6 \% \uparrow)\end{array}$ \\
\hline Compressive strength, $\mathrm{MPa}$ & $184.34 \pm 3.4$ & $\begin{array}{l}188.4 \pm 2.4 \\
(2.2 \% \uparrow)\end{array}$ & $\begin{array}{l}197.65 \pm 1.6 \\
(7.22 \% \uparrow)\end{array}$ & $\begin{array}{l}208.42 \pm 3.1 \\
(13.0 \% \uparrow)\end{array}$ & $\begin{array}{l}227.55 \pm 7.6 \\
(23.4 \% \uparrow)\end{array}$ & $\begin{array}{l}224.3 \pm 0.6 \\
(21.7 \% \uparrow)\end{array}$ \\
\hline Compressive yield, $\mathrm{MPa}$ & $90.09 \pm 0.4$ & $\begin{array}{l}87.77 \pm 4.3 \\
(2.5 \% \downarrow)\end{array}$ & $\begin{array}{l}88.25 \pm 1.3 \\
(2.0 \% \downarrow)\end{array}$ & $\begin{array}{l}88.36 \pm 2.12 \\
(1.9 \% \downarrow)\end{array}$ & $\begin{array}{l}91.40 \pm 1.3 \\
(1.45 \% \uparrow)\end{array}$ & $\begin{array}{l}90.31 \pm 2.4 \\
(0.2 \% \uparrow)\end{array}$ \\
\hline Compressive failure strain, $\%$ & $45.14 \pm 0.5$ & $\begin{array}{l}41.87 \pm 0.2 \\
(7.2 \% \downarrow)\end{array}$ & $\begin{array}{l}47.16 \pm 0.3 \\
(4.4 \% \uparrow)\end{array}$ & $\begin{array}{l}43.55 \pm 0.25 \\
(3.5 \% \downarrow)\end{array}$ & $\begin{array}{l}47.88 \pm 0.33 \\
(6.0 \% \uparrow)\end{array}$ & $\begin{array}{l}48.23 \pm 0.78 \\
(6.8 \% \uparrow)\end{array}$ \\
\hline
\end{tabular}

(a)

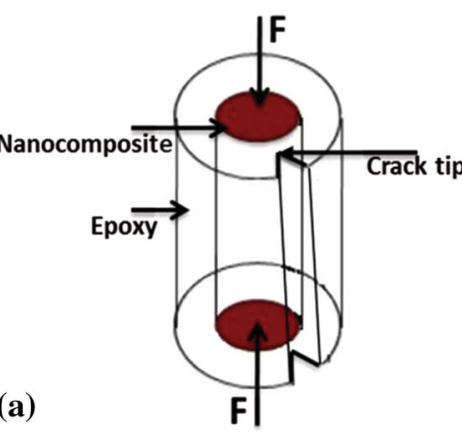

(c)

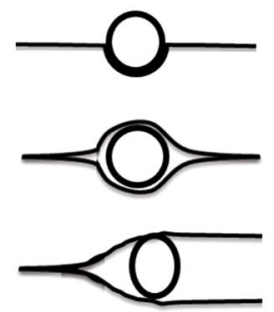

(b)

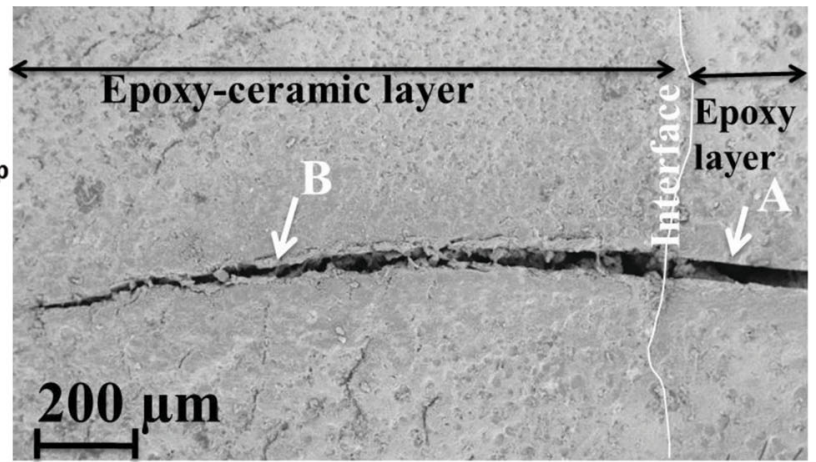

Fig. 8 Bilayer fracture of epoxy- $\mathrm{Ce}_{0.75} \mathrm{Zr}_{0.25} \mathrm{O}_{2}$ nanocomposites under compression

ness test was performed using a compression bilayer cylindrical specimen as shown in Fig. 8(a). The cylindrical specimen under compression has an outer layer of pure epoxy and the nanocomposite in the inner core. Under compression, the crack opens due to hoop stress and the crack enters from the outer layer to the inner layer. Fracture surfaces were observed using FESEM to examine the fractured surface morphology. Figure 8 (b) shows the FESEM image of the crack tip area. As shown in Fig. 8(b, A), the fracture surface of neat epoxy is featureless with a smooth surface, consistent with its typical 
brittle fracture behavior. The characteristic brittleness and low fracture toughness of cured epoxy are the result of high crosslink density of cured epoxy, which causes low absorption of energy during fracture. With the addition of $\mathrm{Ce}_{0.75} \mathrm{Zr}_{0.25} \mathrm{O}_{2}$ nanoparticles, the fracture surface shows more irregular, coarse and multi-plane surface features as seen in Fig. 8(b, B), consistent with higher fracture toughness of nanocomposites compared to neat polymer matrix. As shown in Fig. 8(c), the increase in crack kinking around the nanoparticle can be clearly observed from surface of the nanocomposite, which is a possible reason for the increase in the fracture toughness along the bilayer cylindrical surface. Also we can see the internal crack regions in higher-magnification images, which show the debonding process during fracture due to nano-sized particles. However, debonding is important because this reduces the restriction at the crack tip and hence allows the matrix to deform plastically via a void growth mechanism. Figure $8(\mathrm{~b}, \mathrm{~B})$ shows the evidence of voids around the nanoparticles debond during fracture, which we cannot observe in pure epoxy shown in Fig. 8(b, A). This is expected to be a combined effect of nanocomposite geometry for crack kinking, void growth mechanism. Also due to inhibitory effect of the nanoparticle in the matrix cross-linking and presence of oxide to the polymer cross-linking showed in Energy Dispersive Spectroscopy (EDS) mapping.

The burnout test results reported in Fig. 9(a) clearly suggest the minimum oxidation of $10 \mathrm{wt} \%$ in $\mathrm{Ce}_{x} \mathrm{Zr}_{1-x} \mathrm{O}_{2}$-epoxy composite due to high vapor pressure of ceria. A significant degradation occurred between 300 and $325^{\circ} \mathrm{C}$. This is due to oxidation reactions involving aliphatic bridges that bonded the aromatic rings of the matrix and breaking of bonds between rings and aliphatic bridges/phenolic hydroxyl groups. The elastic modulus and loss factor versus temperature for the cured pure epoxy and epoxy nanocomposite filled with $5 \mathrm{wt} . \%$ $\mathrm{Ce}_{0.75} \mathrm{Zr}_{0.25} \mathrm{O}_{2}$ are shown in Fig. 9(b). It shows the elastic modulus of epoxy-5 wt. $\% \mathrm{Ce}_{0.75} \mathrm{Zr}_{0.25} \mathrm{O}_{2}$ composite which is little higher than pure epoxy. Figure 9(b) shows a slight increase in the glass transition temperature $T_{\mathrm{g}}$ of the epoxy5 wt. $\% \mathrm{Ce}_{0.75} \mathrm{Zr}_{0.25} \mathrm{O}_{2}$ composite compared to that of pure epoxy. The glass transition temperature of cured pure epoxy and epoxy with nanocomposite reinforced with $\mathrm{Ce}_{0.75} \mathrm{Zr}_{0.25} \mathrm{O}_{2}$ nanoparticle loading of 5 wt. $\%$ is $127.8{ }^{\circ} \mathrm{C}$, which is $4.1^{\circ} \mathrm{C}$ higher than that of cured epoxy $\left(123.7^{\circ} \mathrm{C}\right)$. Increased $T_{\mathrm{g}}$ is associated with the increased cross-linking degree of the materials, which means $\mathrm{Ce}_{0.75} \mathrm{Zr}_{0.25} \mathrm{O}_{2}$ nanoparticle could restrict the mobility of the polymer chain and promote the curing process (Ref 35,36$)$.

\subsection{Effect of Nanocomposite Matrix in GFRP Laminate}

From last few decades, the development of polymer nanocomposites such as epoxy nanocomposites delivers new opportunities to explore new fracture behavior and multifunctionality beyond those found in conventional FRP composites. The mechanisms for increasing their modulus of elasticity, tensile strength, ductility, and fracture toughness of polymers via incorporation of micro-/nano-sized particles have been extensively studied (Ref 37 ). In addition, most studies attributed the role of the enormous surface area of nanofillers; however, most of polymer nanocomposites exhibited partly agglomerated dispersion of nanofillers, and few systems could achieve full dispersion. Here we intended to characterize the fiber-reinforced composite with a matrix modified with uniformly dispersed mixed metal oxide nanoparticles to improve mechanical properties, particulary interfacial bonding between fiber and matrix. It is observed that for the $5 \mathrm{wt} . \%$ $\mathrm{Ce}_{0.75} \mathrm{Zr}_{0.25} \mathrm{O}_{2}$ nanoparticles in the epoxy matrix, the tensile modulus and strength of the epoxy composite improved slightly

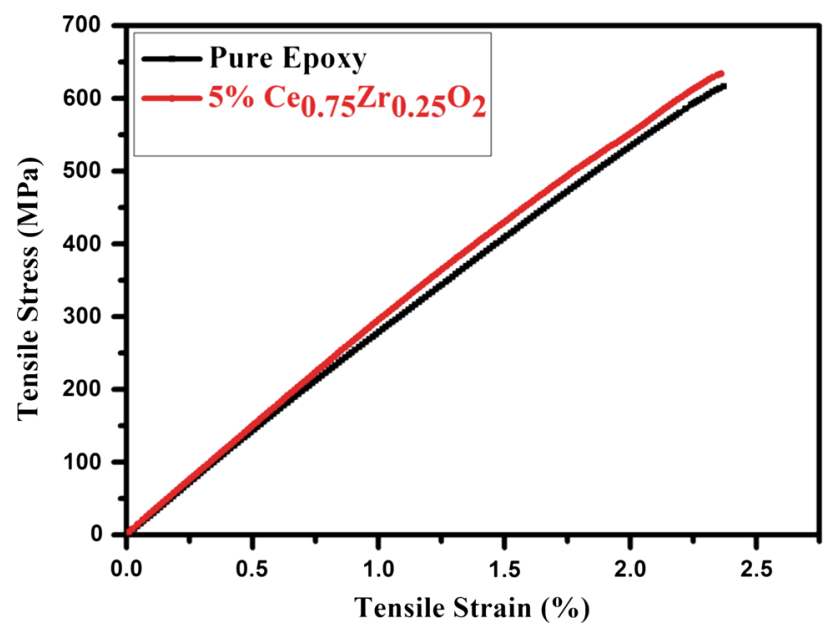

Fig. 10 Tensile stress-strain graphs of pure epoxy and epoxy5 wt.\% $\mathrm{Ce}_{0.75} \mathrm{Zr}_{0.25} \mathrm{O}_{2}$ nanocomposite

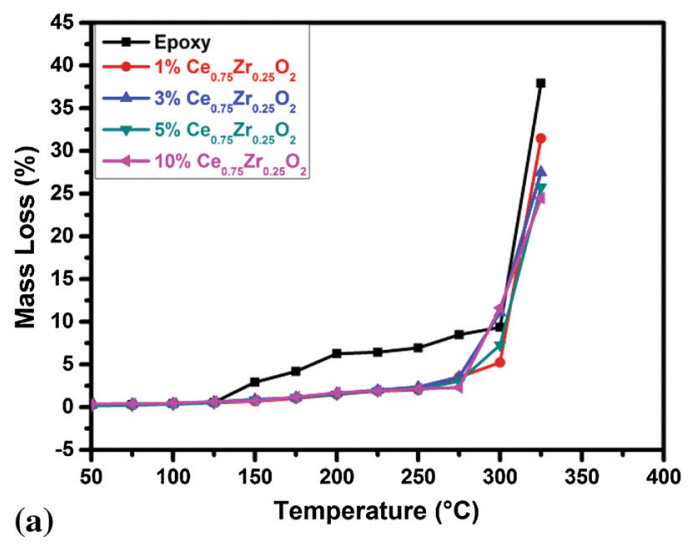

(a)

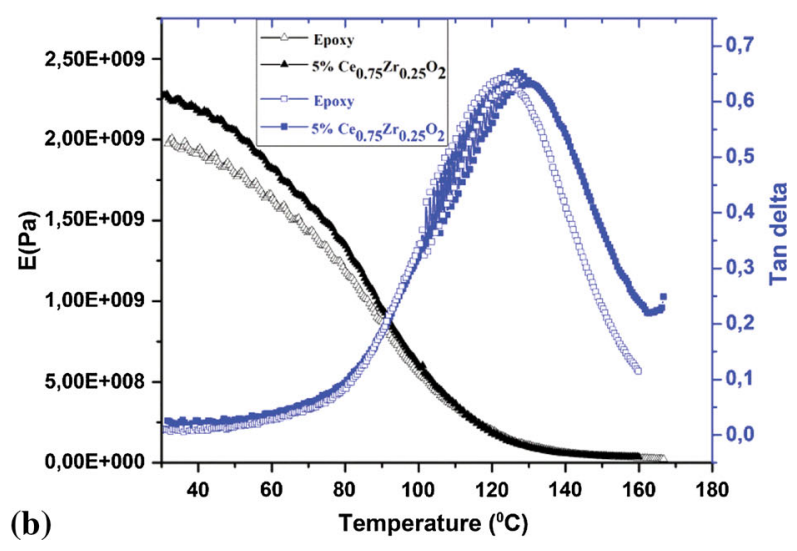

(b)

Fig. 9 (a) Burnout results for epoxy- $\left(x\right.$ wt.\% $\left.\mathrm{Ce}_{0.75} \mathrm{Zr}_{0.25} \mathrm{O}_{2}\right)$ composites compared to epoxy, (b) dynamic elastic property of pure epoxy and epoxy- $\left(5\right.$ wt. $\left.\% \mathrm{Ce}_{0.75} \mathrm{Zr}_{0.25} \mathrm{O}_{2}\right)$ 

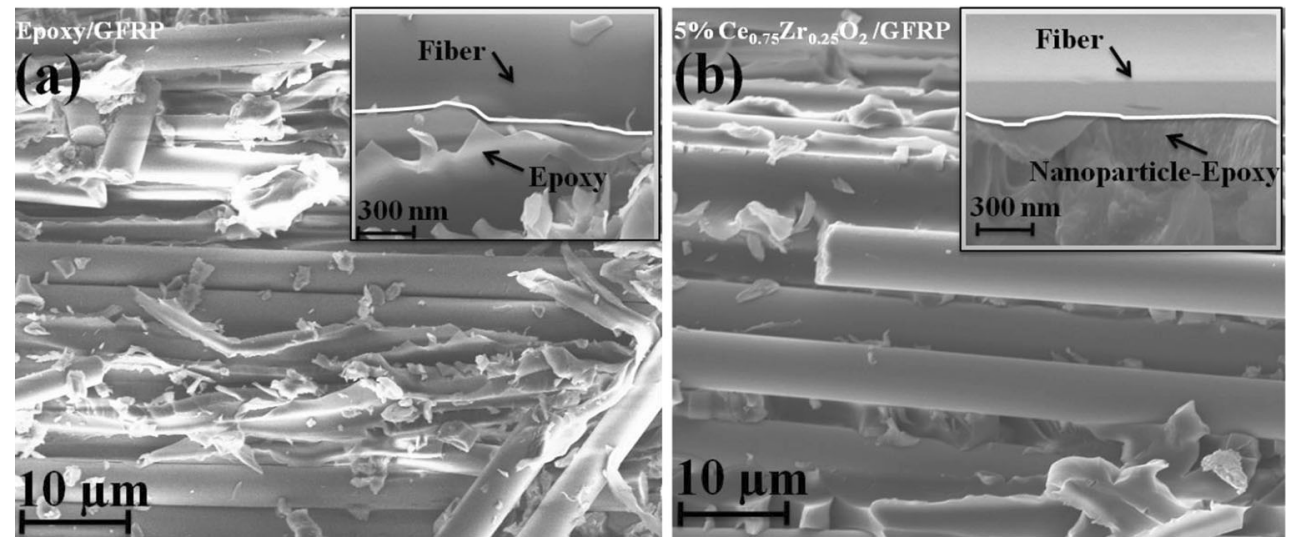

Fig. 11 FESEM images of (a) epoxy/GFRP and (b) $\mathrm{Ce}_{0.75} \mathrm{Zr}_{0.25} \mathrm{O}_{2} / \mathrm{GFRP}$ nanocomposites after tensile fracture

(Fig. 10). This may be due to the strong interface between metal oxide and matrix to fiber. To further understand the enhancing mechanism, the failure surfaces of the samples were examined using SEM. Figure 11 shows the morphology of the tensile-fractured GFRP matrix composite with 5 wt. $\% \mathrm{Ce}_{0.75}$ $\mathrm{Zr}_{0.25} \mathrm{O}_{2}$. It is evident from Fig. 11(a) that the layers of polymer and glass fibers staked one over another formed good bonding. It is clear that glass fibers are well embedded in epoxy, which improves the mechanical properties of the composites with usual fracture initiated from matrix cracking. In optimized 5 wt.\% of the $\mathrm{Ce}_{0.75} \mathrm{Zr}_{0.25} \mathrm{O}_{2}$ nanoparticles interfaces which are formed inside the composite and are close to fibers are shown in Fig. 11(b). No or very little micro-cracks are observed with a small amount of shear bonding as compared to that at epoxy, which suggests a relatively strong interfacial bonding, control of the local stress concentration, and good compatibility of $\mathrm{Ce}_{0.75} \mathrm{Zr}_{0.25} \mathrm{O}_{2}$ particles with the fiber interface. From the SEM observations, it appears that the nanocomposites possess better interfacial bonding than the conventional one. Finally, it is concluded that the influence of mixed metal oxide nanoparticle reinforcements indicates that the interfacial bonding between matrix/fiber enhances the final structure of the mechanical properties.

\section{Conclusions}

XRD study shows, except pure $\mathrm{ZrO}_{2}$ all other samples are well crystalline and cubic fluorite phase with the composition $\mathrm{Ce}_{0.75} \mathrm{Zr}_{0.25} \mathrm{O}_{2}$ is observed with optimal influence on mechanical properties of the epoxy matrix system. Average particle size ranged between 10 and $20 \mathrm{~nm}$, which confirms the monodispersed system of 5 wt. $\% \mathrm{Ce}_{0.75} \mathrm{Zr}_{0.25} \mathrm{O}_{2}$ particles. The overall mechanical properties of the nanocomposite matrix are improved with 5 wt. $\% \mathrm{Ce}_{0.75} \mathrm{Zr}_{0.25} \mathrm{O}_{2}$. With the addition of 5 wt. $\% \mathrm{Ce}_{0.75} \mathrm{Zr}_{0.25} \mathrm{O}_{2}$, the fracture toughness enhancement due to the toughening mechanisms via crack kinking, void growth mechanism and interface addition are confirmed. The elastic modulus, glass transition temperature and loss factor of the nanocomposite were improved. Tensile strength and modulus of nanocomposite/GFRP system show a marginal increase. Micro-cracks are minimized at the fiber interface of GFRP, which suggests a relatively strong interfacial bonding, control of the local stress concentration, and good compatibility of $\mathrm{Ce}_{0.75} \mathrm{Zr}_{0.25} \mathrm{O}_{2}$ particles.

\section{Acknowledgments}

Authors acknowledge the financial support under the ACECOST phase-III program of the Aeronautics Research and Development Board to carry out this research.

\section{References}

1. I.A. Al Ajaj, M.M. Abd, and H.I. Jaffer, Mechanical Properties of Micro and $\mathrm{Nano} \mathrm{TiO}_{2}$ /Epoxy Composites, IJMMME, 2013, 2, p 2320 4060

2. B. Bittmann, F. Haupert, and A.K. Schlarb, Preparation of $\mathrm{TiO}_{2} /$ Epoxy Nanocomposites by Ultrasonic Dispersion and Their Structure Property Relationship, Ultrason. Sonochem., 2011, 18, p 120-126

3. Y. Zheng, Y. Zheng, and R. Ning, Effects of Nanoparticles $\mathrm{SiO}_{2}$ on the Performance of Nanocomposites, Mater. Lett., 2013, 57, p 2940-2944

4. A. Omrani, L.C. Simon, and A. Rostami, The Effects of Alumina Nanoparticle on the Properties of an Epoxy Resin System, Mater. Chem. Phys., 2009, 114, p 145-150

5. T.R. Prabhu, S. Basavarajappa, R.B. Santhosh, and S.M. Ashwini, Tribological and Mechanical Behaviour of Dual-Particle (Nanoclay and $\mathrm{CaSiO}_{3}$ )-Reinforced E-Glass-Reinforced Epoxy Nanocomposites, Bull. Mater. Sci., 2017, 40, p 107-116

6. V. Arrighi, I.J. McEwen, H. Qian, and M.B. Serrano Prieto, The Glass Transition and Interfacial Layer in Styrene-Butadiene Rubber Containing Silica Nanofiller, Polymer, 2003, 44, p 6259-6266

7. Z. Guo, K. Lei, Y. Li, H.W. Ng, S. Prikhodko, and H.T. Hahn, Fabrication and Characterization of Iron Oxide Nanoparticles Reinforced Vinyl-Ester Resin Nanocomposites, Compos. Sci. Technol., 2008, 68, p 1513-1520

8. Z. Guo, T. Pereira, O. Choi, Y. Wang, and H.T. Hahn, Surface Functionalized Alumina Nanoparticle Filled Polymeric Nanocomposites with Enhanced Mechanical Properties, J. Mater. Chem., 2006, 16, p 2800-2808

9. H.J. Kim, D.H. Jung, I.H. Jung, J.I. Cifuentes, K.Y. Rhee, and D. Hui, Enhancement of Mechanical Properties of Aluminium/Epoxy Composites with Silane Functionalization of Aluminium Powder, Composites $B, 2012, \mathbf{4 3}, \mathrm{p} 1743-1748$

10. G. Zhang, G. Xie, J. Wang, L. Si, D. Guo, S. Wen, and F. Yang, Controlled Friction Behaviors of Porous Copper/Graphite Storing Ionic Liquid through Electrical Stimulation, Adv. Eng. Mater., 2017, 20(5), p 1700866

11. G. Zhang, G. Xie, L. Si, S. Wen, and D. Guo, Ultralow Friction SelfLubricating Nanocomposites with Mesoporous Metal-Organic Frameworks as Smart Nanocontainers for Lubricants, ACS Appl. Mater. Interfaces, 2017, 9, p 38146-38152

12. T.M. Pollock, D.M. Lipkin, and K.J. Hemker, Multifunctional Coating Interlayers for thermal-Barrier Systems, MRS Bull., 2012, 37, p 923-931

13. P. Nitin, G. Maurice, and H.J. Eric, Thermal Barrier Coatings for GasTurbine Engine Applications, Science, 2002, 296, p 280-284

14. L. Yves, Durability of Nanosized Oxygen-Barrier Coatings on Polymers, Prog. Mater Sci., 2003, 48, p 1-55 
15. C.P.F. Crissia, T.B.N. Annibal, P.S. Adelina, and O.F. Luiz, P(VDF$\mathrm{TrFE}) / \mathrm{ZrO}_{2}$ Polymer-Composites for X-Ray Shielding, Mater. Res., 2016, 19, p 426-433

16. B. Ma, Y. Li, and K. Su, Characterization of Ceria-Yttria Stabilized Zirconia Plasma-Sprayed Coatings, Appl. Surf. Sci., 2009, 255, p 7234-7237

17. S.K. Tadokoro and E.N.S. Muccillo, Physical Characteristics and Sintering Behavior of Ultrafine Zirconia-Ceria Powders, J. Eur. Ceram. Soc., 2002, 22, p 1723-1728

18. W. Huang, C. Wang, J. Yang, B. Zou, X. Meng, Y. Wang, X. Cao, and $\mathrm{Z}$. Wang, Effect of $\mathrm{Zr} / \mathrm{Ce}$ Molar Ratio on the Structure of Powders and $\mathrm{Zr}_{1-x} \mathrm{Ce}_{x} \mathrm{O}_{2}$ Coatings on Quartz Fiber Reinforced Polyimide Matrix Composites via Sol-Gel Process, J. Sol Gel Sci. Technol., 2012, 61, p 213-223

19. K.V. Pochiraju, G.P. Tandon, and G.A. Schoeppner, Long-Term Durability of Polymeric Matrix Composites, 1st ed., Springer, Berlin, 2012, p 1-677

20. X.F. Yao, H.Y. Yeh, D. Zhou, and A.H. Zhang, The Structural Characterization and Properties of $\mathrm{SiO}_{2}$-Epoxy Nanocomposites, $J$. Compos. Mater, 2006, 40, p 371-381

21. V.K. Rangari, T.A. Hassan, Q. Mayo, and S. Jeelani, Size Reduction of $\mathrm{WO}_{3}$ Nanoparticles by Ultrasound Irradiation and Its Applications in Structural Nanocomposites, Compos. Sci. Technol., 2009, 69, p 2293 2300

22. S. Datta, B.M. Nagabhushana, and R. Harikrishna, A New Nano-ceria Reinforced Epoxy Polymer Composite with Improved Mechanical Properties, IJARET, 2012, 3, p 248-256

23. R. Medina, F. Haupert, and A.K. Schlarb, Improvement of Tensile Properties and Toughness of an Epoxy Resin by NanozirconiumDioxide Reinforcement, J. Mater. Sci., 2008, 43, p 3245-3252

24. S.M. Mirabedini, M. Behzadnasab, and K. Kabiri, Effect of Various Combinations of Zirconia and Organoclay Nanoparticles on Mechanical and Thermal Properties of an Epoxy Nanocomposite Coating, Composites A, 2012, 43, p 2095-2106

25. P. Dittanet and R.A. Pearson, Effect of Silica Nanoparticle Size on Toughening Mechanisms of Filled Epoxy, Polymer, 2012, 53, p 1890 1905
26. M. Sudheer, K.M. Subbaya, D. Jawali, and T. Bhat, Mechanical Properties of Potassium Titanate Whisker Reinforced Epoxy Resin Composites, J. Miner. Mater. Charact. Eng., 2012, 11, p 193-210

27. H.J. Kim, D.H. Jung, I.H. Jung, J.I. Cifuentes, K.Y. Rhee, and D. Hui, Enhancement of Mechanical Properties of Aluminium/Epoxy Composites with Silane Functionalization of Aluminium Powder, Composites $B, 2012, \mathbf{4 3}$, p 1743-1748

28. H. Faleh, R. Al-Mahaidi, and V. Shen, Fabrication and Characterization of Nanoparticle Reinforced Epoxy, Compos. B Eng., 2012, 43, p 30763080

29. A. Toldy, B. Szolnoki, and G.Y. Marosi, Flame Retardancy of FibreReinforced Epoxy Resin Composites for Aerospace Applications, Polym. Degrad. Stab., 2011, 96, p 371-376

30. S. Lu, J. Ban, and K. Liu, Preparation and Characterization of Liquid Crystalline Polyurethane $/ \mathrm{Al}_{2} \mathrm{O}_{3} /$ Epoxy Resin Composites for Electronic Packaging, Int. J. Polym. Sci., 2012, 2012, p 728235

31. Y. He, B.E. Moreira, and A. Overson, Thermal Characterization of an Epoxy-Based Under Fill Material for Flip Chip Packaging, Thermochim. Acta, 2000, 357-358, p 1-8

32. D. Ratna, T.K. Chongdar, and B.C. Chakraborty, Mechanical Characterization of New Glass Fiber Reinforced Epoxy Composites, Polym. Compos., 2004, 25, p 165-171

33. B. Kchaou, C. Turki, and M. Salvia, Dielectric and Friction Behaviour of Unidirectional Glass Fibre Reinforced Epoxy (GFRE), Wear, 2008, 265, p 763-771

34. C.S. Tiwary, S. Kishore, R. Vasireddi, D.R. Mahapatra, P.M. Ajayan, and K. Chattopadhyay, Electronic Waste Recycling via Cryo-Milling and Nanoparticle Beneficiation, Mater. Today, 2017, 20, p 67-73

35. M. Abdalla, D. Dean, M. Theodore, J. Fielding, E. Nyairo, and G. Price, Magnetically Processed Carbon Nanotube/Epoxy Nanocomposites: Morphology, Thermal, and Mechanical Properties, Polymer, 2010, 51(7), p 1614-1620

36. Y. Pan, Y. Xu, L. An, H. Lu, Y. Yang, and W. Chen, Hybrid Network Structure and Mechanical Properties of Rodlike Silicate/Cyanate Ester Nanocomposites, Macromolecules, 2008, 41(23), p 9245-9258

37. J. Njuguna, K. Pielichowski, and S. Desai, Nanofiller-Reinforced Polymer Nanocomposites, Polym. Adv. Technol., 2008, 19(8), p 947-959 